REVIEW ARTICLE

A.K. Bag

J.K. Curé

P.R. Chapman

G.H. Roberson

R. Shah

\section{JC Virus Infection of the Brain}

SUMMARY: Since its initial description, there have been significant changes in the epidemiology, pathogenesis, and clinical and imaging manifestations of JCV infection of brain. The most common clinical manifestation is PML. Other recently described CNS manifestations are JCE, JCVGCN, and JCM. Although AIDS is the most common predisposing factor for JCV reactivation, there is increasing incidence of brain manifestations of JCV reactivation in non-HIV settings, including different rheumatologic, hematologic, and oncologic conditions; monoclonal antibody therapy; transplant recipients; primary immunodeficiency syndromes; and even in patients without any recognizable immune deficiency. IRIS may develop secondary to restoration of immunity in HIV-positive patients with PML receiving antiretroviral therapy. This is of profound clinical significance and needs to be diagnosed promptly. Imaging plays a crucial role in the diagnosis of the disease, monitoring of treatment response, identifying disease progression, and predicting prognosis. In this article, current understanding of the epidemiology, pathogenesis, clinical presentations, and all aspects of imaging of JCV infection of the brain have been comprehensively reviewed.
$\mathbf{T}$ he JCV, a member of the Polyomaviridae family, was first isolated from the brain of a patient with Hodgkin disease in $1971,{ }^{1}$ though the disease was first described by Åström et al in $1958 .^{2}$ The demyelinating encephalopathy caused by the virus was subsequently termed "PML". Until the 1980s, PML was considered an extremely rare opportunistic infection. The HIV pandemic led to a new population of immunosuppressed patients, and the prevalence of PML increased dramatically. Now, HIV-induced immunodeficiency is the most common predisposing factor for symptomatic JCV infection. The surge in HIV-associated PML has led to intense research on JCV infection and resulted in better understanding of its changing epidemiology and expanding clinicopathologic spectrum. Similarly, the imaging manifestations of JCV infection are now known to be more diverse and complex and are significantly altered by novel treatments for HIV and PML. This article presents a comprehensive review of the JCV infection, including PML, and emphasizes the broadening radiologic spectrum related to this infection.

\section{Epidemiology: Population at Risk}

It has become evident that PML has outgrown its name. JCV infection is no longer a 1-dimensional opportunistic infection, limited to HIV and lymphoproliferative disorders. Although

From the Department of Radiology, Division of Neuroradiology, University of Alabama at Birmingham Medical Center, Birmingham, Alabama.

Please address correspondence to Asim K. Bag, MD, Division of Neuroradiology, Department of Radiology, University of Alabama at Birmingham Medical Center, 619 19th St S, WP-150, Birmingham, AL-35249-6830; e-mail: abag@uabmc.edu

Indicates open access to non-subscribers at www.ajnr.org

DOI 10.3174/ajnr.A2035
HIV accounts for approximately $80 \%$ of the PML cases, there is increasing incidence of the disease in non-HIV settings. ${ }^{3}$

JCV is a ubiquitous human pathogen, and both inhalation and ingestion of contaminated water have been suggested as major modes of transmission of the virus. ${ }^{4,5}$ The primary infection is presumably asymptomatic, and $85 \%$ of the adult population has antibodies against JCV, implying previous exposure and potentially latent infection. ${ }^{6}$ Usually, severe deficiency of T-cell immunity (cellular immunity) is necessary for reactivation of JCV. ${ }^{6}$ Suppression of cellular immunity, secondary to HIV infection, is the major cause of the JCV reactivation and constitutes approximately $80 \%$ of patients with PML. Other less common immunodeficiency settings for PML are hematologic malignancies (13\%), organ transplant recipients $(5 \%)$, and autoimmune diseases treated with immunomodulators (3\%). ${ }^{6}$ Epidemiology of JCV infection is described with reference to PML as this is the most common manifestation of JCV infection.

\section{PML in HIV Infection}

At present, immunodeficiency secondary to HIV-1 infection/ AIDS is the most common precipitating condition that leads to JCV reactivation and PML. There are only a handful of reports of PML in the setting of HIV-2. ${ }^{7,8}$ This discrepancy may be due to variable geographic prevalence of HIV-2 infection, which is distinctly more common in African compared with Western countries. ${ }^{7}$ Sophisticated technologies required for confirmatory diagnosis of PML are not readily available in most developing countries, and the incidence may be artificially reduced accordingly.

HAART has become a central component in the therapy for HIV, leading to markedly improved survival times. 
HAART has substantially reduced the incidence of PML. ${ }^{9}$ In the pre-HAART era, PML affected $3 \%-7 \%$ of patients with HIV-1 infection and was the cause of up to $18 \%$ of fatal CNS disease. $^{10,11}$ The incidence of PML has decreased from 0.7 per 100 person-years of follow-up in 1994 to 0.07 in 2001-2002. ${ }^{11}$ Unlike many other CNS opportunistic infections, JCV infection occurs early in the course of AIDS with CD4 cell counts $>200 / \mu \mathrm{L}$ and can also occur in patients receiving HAART. ${ }^{12}$ One-year survival time in HIV patients with PML has also increased considerably, from $0 \%$ to $30 \%$ in the pre-HAART era to $38 \%-62 \%$ with HAART. ${ }^{13,14}$ However, according to a 2005 survey, PML is still the second most common cause (14\%) of all AIDS-related death, second only to non-Hodgkin lymphoma. ${ }^{14}$

\section{PML in Hematologic and Oncologic Conditions}

PML was originally described in patients with chronic lymphocytic leukemia and Hodgkin disease in $1958 .^{2}$ GarciaSuarez et $\mathrm{al}^{15}$ reviewed all the reported cases of PML in lymphoproliferative disorders published between 1958 and 2004. In this extensive review, PML was linked to chronic lymphocytic lymphoma, Hodgkin disease, non-Hodgkin lymphoma, Waldeström macroglobulinemia, multiple myeloma, and mycosis fungoides. Major risk factors for PML in this setting were uncontrolled Hodgkin disease, treatment with purine analogues, and stem cell transplantation.

\section{PML in Organ Transplantation}

Organ transplantation, a setting of iatrogenic immune deficiency, is not uncommonly associated with PML. Median time to onset of the disease is 17 months, somewhat longer in patients with renal transplants due to less intense immune suppression. ${ }^{16}$ PML has also been described in patients with stem cell transplantation, both autologous and allogenic. ${ }^{17}$

\section{PML in Rheumatologic Conditions}

Calabrese et $\mathrm{al}^{18}$ recently reviewed 37 cases of PML in the setting of rheumatic diseases. All patients in this series were treated with some form of immunosuppressant before PML manifestation. Of all the rheumatologic conditions SLE was most commonly associated (65\%) with PML. Other associated rheumatic diseases were rheumatoid arthritis, Wegener granulomatosis, dermatomyositis, polymyositis, and scleroderma. There are also reports of PML in patients with Sjogren syndrome $^{19}$ and sarcoidosis ${ }^{20}$ with no prior immunomodulator therapy. In both of these cases, there was associated lymphocytopenia. It is unclear whether the rheumatologic condition or the lymphocytopenia was responsible for PML.

\section{PML in the Setting of mAb Therapy}

In recent years, $\mathrm{mAbs}$ are being used in a wide spectrum of immunologic diseases. Some of the mAbs depress the immune system and, as a result, predispose the patient to PML. Association of natalizumab (an mAb against the $\alpha 4$-integrin of the cell adhesion molecule family, used primarily to treat MS and Crohn disease), and PML has been extensively discussed in the medical literature. ${ }^{21-23}$ Other mAbs associated with PML are efalizumab $^{24}$ (an mAb that binds to CD11a, used primarily to treat psoriasis) and rituximab ${ }^{25}$ (an mAb against CD20 used in many clinical conditions). Approximately 57 cases of PML have been described in patients receiving rituximab for the treatment of hematologic malignancy (predominantly nonHodgkins lymphoma) $(n=50)$, rheumatoid arthritis $(n=1)$, SLE $(n=2)$, and autoimmune hematologic disorder $(n=$ $4) .^{26,27}$

\section{PML in Idiopathic Immune Deficiency Syndrome}

PML has also been described in patients with primary immunodeficiency disorders, ICL being the most common condition to be associated with PML. ${ }^{28-30}$ PML has also been described in patients with common variable immune deficiency. ${ }^{31,32}$

\section{PML in the Setting of Minimal/No Immunodeficiency}

Until recently, severe depletion of cellular immunity was considered an absolute requirement for the development of PML. However, there are now case reports of PML with less overt immunodeficiency, such as cirrhosis, renal failure, psoriasis, dermatomyositis, and even pregnancy. ${ }^{6}$ Furthermore, there are multiple reports in the literature of PML without any documented immunodeficiency. ${ }^{6}$ It is very important that neuroradiologists be aware of this expanding demography of PML, JCE, JCVGCN, and JCM. So far, both JCE and JCVGCN have been described in the setting of HIV infection/AIDS. Interestingly, all the reported cases of JCM have been reported in non-HIV settings including SLE and even immunocompetent patient as elaborated in the pathogenesis section.

\section{Pathogenesis}

JCV is a double-stranded circular DNA virus and a member of the Polyomaviridae family. This is a small virus with icosahedral symmetry. The capsid contains 3 viral proteins, VP1, VP2, and VP3, of which VP1 is the most abundant and can present itself to the host immune system as a viruslike particle. ${ }^{33,34}$

The pathogenesis of PML is divided into 3 phases. The first phase is a primary clinically unapparent infection. In the second phase, the virus maintains a persistent latent peripheral infection in the urinary tract, bone marrow, and probably the spleen. ${ }^{35}$ The presence of JCV in the bone marrow and shedding of the virus in urine are well documented in asymptomatic immunocompetent carriers. ${ }^{36,37}$ The CNS has also been suggested as a potential site for JCV persistence. The third or final phase is that of reactivation and dissemination of the virus with presumed hematogenous spread to the CNS. ${ }^{35}$ The route and time when the virus reaches the CNS are not known exactly. The spread is most likely hematogenous and may either be during primary infection, during peripheral persistence phase or during reactivation of the virus when cellular immunity is impaired. ${ }^{38}$

In the phase of persistent infection, the virus harbors a stable and nonpathologic RR in its DNA between the early and late protein-coding regions called archetype. With decreased level of host T-cell immunity, there is rearrangement of this archetype RR, resulting in JCV reactivation, which leads to a lytic infection of oligodendrocytes. ${ }^{39}$ Individuals with a depressed or suppressed cellular immunity rather than suppressed humoral immunity are at particular risk for PML development. CD8 + T-lymphocytes are effector cells of cellular immunity, also known as CTL. These CTLs kill the virus-infected cells if they recognize properly processed viral epitopes 


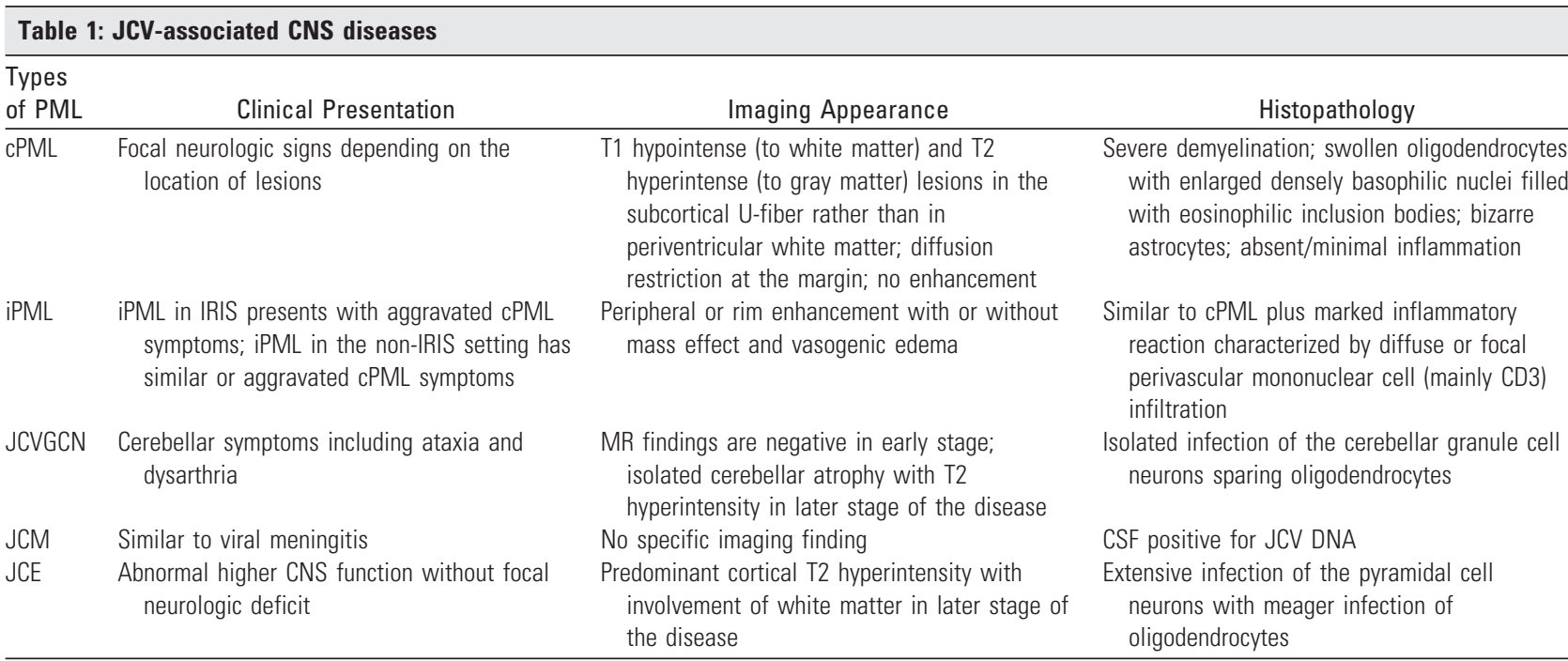

(a macromolecule, or part of a macromolecule derived from the virus that is recognized by the host immune system). The presence of JCV-specific CTLs in blood or CSF reduces the risk for the development of the disease and improves prognosis. This emphasizes the crucial role of these CTLs in mounting immunity against the JCV. ${ }^{40}$ The striking association of disease with HIV infection and its occurrence in ICL in the absence of HIV infection suggest that CD4 + T-cells also play an important role against JCV. ${ }^{41}$ Conversely, humoral immunity is not protective against JCV infection.

The importance of intact host immunity is clear from both the context of PML in patients with immune defects and its remission after HAART. ${ }^{42,43}$ Remission of the disease is often associated with re-establishment of CD4+ cells and CTLs in the blood and CSF. ${ }^{44-46}$

\section{Clinicopathologic Syndromes of CNS JCV infection}

Until recently, PML was the only known manifestation of CNS JCV infection with nonspecific clinical presentations but typical histopathologic and imaging findings. With restoration of immunity with HAART, there may be an abrupt change in the clinical behavior and histopathologic and imaging manifestations of PML in some patients. This altered presentation has profound clinical significance and needs to be differentiated from the classic presentation. Also 3 new CNS manifestations of JCV infection have been recently recognized and described. For better understanding, all the manifestations of JCV infection are classified below (Table 1).

\section{cPML}

Clinical presentations of PML are nonspecific. In approximately $25 \%$ of patients, PML is the initial AIDS-defining illness. ${ }^{47}$ The cPML presentation begins with focal neurologic deficits that depend on the location of the lesions. Most commonly, patients present with hemiparesis or hemisensory defects. There may be visual problems if there is occipital lobe or optic radiation involvement, language problems if there is involvement of the dominant parietal lobe, and ataxia or dysmetria if there is cerebellar involvement and so forth. ${ }^{35}$ Usually initial symptoms are partial and gradually worsen, depending on the area of brain involved as lesions enlarge. Approximately
$20 \%$ of patients develop seizures in addition to the focal neurologic symptoms. ${ }^{48}$ Patients may also present with cognitive deficits. Occasionally, it may be very difficult to differentiate PML from HIV encephalopathy on the basis of clinical presentation.

Histopathologically, the principal feature is demyelination. Initial foci of demyelination expand and coalesce into larger areas. In advanced cases, lesions may undergo central cavitary necrosis. ${ }^{38}$ Characteristic histopathologic findings are lytic infection of the oligodendrocytes, which are swollen with enlarged densely basophilic nuclei filled with eosinophilic inclusion bodies and positive staining of the infected oligodendrocytes/nuclei for JCV proteins and nucleic acids. ${ }^{38}$ The classic infected oligodendrocytes are seen predominantly at the advancing margin of the lesion. ${ }^{49}$ The oligodendrocytes swell at the expense of extracellular space, which explains diffusion restriction on DWI in the active margin of the lesions. JCV also infects the astrocytes, which are also enlarged, containing numerous enlarged processes. These swollen astrocytes also contain JCV protein and/or gene products. Sometimes enlarged astrocytes contain multilobulated hyperchromatic nuclei, resembling neoplastic cells, which pathologists refer to as "'bizarre astrocytes." ${ }^{50}$ Another characteristic histopathologic finding of PML is mild or absent inflammation. ${ }^{50}$ Vary rarely, there may be hemorrhage within the lesions. ${ }^{51}$

\section{iPML}

cPML, as stated earlier, is typically characterized by a distinct lack of inflammatory change in the affected brain tissue. Rarely, reactivation of the JCV and development of PML can be associated with a marked inflammatory reaction. These lesions are characterized by either diffuse or focal perivascular mononuclear infiltrates, mostly of CD3 T-cells, monocytes, or macrophages and B-lymphocytes, CD4 T-cells, and plasma cells. ${ }^{52-54}$ Radiologically, the lesions are characterized by contrast enhancement or/and mass effect with vasogenic edema.

There may be 2 different settings of the iPML. More commonly, iPML develops in the setting of IRIS in HIV-positive patients following treatment with HAART (see "IRIS and NIRIS"). As expected, patients with IRIS-associated iPML generally have worsening of the neurologic symptoms of 
CPML. iPML may rarely be the presenting phenotype in nonHIV patients ${ }^{52}$, as well as in HIV-positive patients without HAART. iPML in non-HIV setting has worse prognosis. ${ }^{52}$

\section{JCVGCN}

Posterior fossa involvement is frequent both in $\mathrm{CPML}$ and iPML. Posterior fossa lesions typically affect the middle cerebellar peduncles and adjacent pons and/or cerebellar hemispheres. There is another cerebellar manifestation of JCV, the JCVGCN, ${ }^{55}$ which infects only cerebellar granule cell neurons, sparing the oligodendrocytes. The classic histopathologic appearances of PML with oligodendrocytic and astrocytic changes are, therefore, not present in this condition. Patients present with isolated cerebellar symptoms, including ataxia and dysarthria. Tropism for cerebellar granular cells is believed to be due to a unique mutation of the VP1 gene of the virus. $^{56}$

\section{JCM}

CSF testing for JCV or JCV DNA is not routinely performed in the work-up of a patient presenting with clinical symptoms of viral meningitis. Blake et $\mathrm{al}^{57}$ first described JCV associated with meningoencephalitis in an immunocompetent girl in 1992. They supported their hypothesis with increasing titers of JCV immunoglobulin $\mathrm{G}$ and immunoglobulin $\mathrm{M}$. In a large study, JCV DNA was identified from the CSF of 2 of the 89 patients (19 HIV-positive and $70 \mathrm{HIV}$-negative) being evaluated for meningitis. ${ }^{58}$ Both the JCV-positive patients were from HIV-negative group. The authors concluded that tests for BK virus and JCV should be included in the investigative program for patients with meningitis or encephalitis. Viallard et $\mathrm{al}^{59}$ reported a patient with a long history of SLE who presented with acute meningitis with no history of encephalitis or PML. In an extensive work-up of the patient, the authors found that JCV was the only pathogen identified in the CSF. The authors concluded that if CNS infection is suspected in patients with SLE, JCV infection should be considered in the differential diagnoses. CSF PCR for JCV DNA should be rapidly performed to initiate prompt antiviral therapy.

\section{JCE}

$\mathrm{JCE}^{60}$ is a newly described encephalopathic form of CNS infection by JCV. Wüthrich et $\mathrm{al}^{60}$ reported a patient with abnormality of higher CNS functions with no focal neurologic deficit. On histology, there was preferential infection of the cortical pyramidal neurons and astrocytes located in the cortical gray matter and gray-white junction with areas of necrosis. The authors found extensive infection of the pyramidal cell neurons and confirmed JCV proteins in the nuclei, axons, and dendrites of pyramidal cell neurons by using double immunostaining methods. Although there was white matter involvement on MR imaging in the late stage, there was only meager infection of the oligodendrocytes without the "typical" demyelination found in PML.

\section{IRIS and NIRIS}

IRIS is paradoxic deterioration of clinical response encountered in HIV-infected patients who have received HAART. The diagnosis is often challenging, treatment options are limited, and the prognosis is variable. ${ }^{61}$ The diagnosis of IRIS is advocated when a patient meets the following criteria $^{62}$ : known HIV-positive patient receiving HAART with a decrease in the HIV-1 ribonucleic acid level from baseline and an increase in CD4 + cells from baseline with clinical symptoms consistent with an inflammatory process rather than an expected course of previously diagnosed opportunistic infection or the expected course of newly diagnosed opportunistic infection or drug toxicity. In the CNS context, the disease may be called NIRIS.

Patients who are antiretroviral naïve are particularly at risk for IRIS. ${ }^{63,64}$ Other risk factors include the duration and extent of immunodeficiency, polymorphisms in cytokine genes, ${ }^{65}$ high initial viral load, and the velocity of immune reconstitution. ${ }^{66}$ No difference in the risk of developing IRIS has been observed when comparing different drug regimens. ${ }^{63}$ However, initiation of HAART soon after the diagnosis of opportunistic infection may be a clinical predictor of IRIS. ${ }^{67}$

IRIS may occur during either of the 2 phases of immune restitution that occur after the initiation of HAART. ${ }^{68}$ The first period of susceptibility occurs in the initial weeks when the increase in CD4 T-cells is largely due to the redistribution of pre-existing memory $\mathrm{T}$-cells. The late phase is a direct result of the proliferation of naïve T-cells, usually after 4-6 weeks but can be as long as 4 years after the initiation of HAART. ${ }^{69}$

HAART-induced restoration of a pathogen-specific immune response contributes to the pathologic recognition of JCV antigens either in already manifested PML (phase 3 of the pathogenesis) or in the persistent infection phase (phase 2 of the pathogenesis) of PML. ${ }^{70}$ Although histopathologic criteria have not yet been defined, IRIS is often dominated by CD8+ T-lymphocyte inflammatory infiltrates. Mycobacterial infections are the most common IRIS-associated infection elsewhere in the body. ${ }^{71,72}$ However, in the CNS, the most common inciting agent is JCV. ${ }^{42,72}$ Less common IRIS-associated pathogens are Cryptococcus, ${ }^{73,74}$ herpes virus, and cytomegalovirus. ${ }^{68}$ Rarely, autoimmune diseases and neoplasia may also incite IRIS. ${ }^{73}$

PML-IRIS accounts for as many as $18 \%$ of the HIV-infected patients with PML. ${ }^{75}$ As noted previously, PML and IRIS may develop simultaneously in neurologically healthy patients with the start of HAART (unmasking IRIS) or there may be worsening neurologic symptoms in patients with previously manifested PML due to development of IRIS following initiation of HAART (paradoxic IRIS).$^{76}$ Although there is no demographic difference between these 2 cohorts of patients, the latter group progresses to IRIS during a shorter period compared with the first group, probably due to greater lesion loads. ${ }^{77}$ Most PML-IRIS cases are characterized by mild symptoms and limited CNS inflammation.

The typical histopathologic appearance of PML-IRIS is hypercellular gray and white matter with gliosis, atypical hyperchromatic astrocytic nuclei, macrophages, and moderate perivascular inflammation, which explains enhancement on contrast-enhanced MR imaging, unlike cPML. While contrast enhancement may be considered as a surrogate marker for the development PML-IRIS, it is present in only $56 \%$ of patients. ${ }^{77}$ Therefore, nonenhancement of a PML lesion with clinical deterioration does not preclude the diagnosis. Unfortunately, to date, there is no biomarker to confirm development of IRIS.

Ironically, PML-IRIS is treated with steroids and a tran- 


\begin{tabular}{|c|c|c|c|c|}
\hline & $\begin{array}{l}\text { Typical } \\
\text { Clinical }\end{array}$ & $\begin{array}{l}\text { Typical } \\
\text { Imaging }\end{array}$ & $\begin{array}{l}\text { CSF } \\
\text { JCV }\end{array}$ & $\begin{array}{l}\text { Typical Histopathology } \\
\text { with Demonstration of }\end{array}$ \\
\hline Diagnosis & Feature & Feature & DNA & JCV DNA/Protein \\
\hline Definite PML & + & + & + & - \\
\hline Definite PML & + & + & - & + \\
\hline Presumptive PML & + & + & - & - \\
\hline
\end{tabular}

Note:-+ indicates present; -, absent.

sient antiretroviral drug holiday. PML-IRIS has a favorable outcome if treated appropriately with steroids. ${ }^{77}$

\section{Diagnosis}

Early diagnosis of PML or other JCV-associated CNS infection is of profound importance due to recent expansion of populations of individuals at risk for JCV infection. Even though highly sensitive tests for JCV DNA detection are available and there are specific imaging findings, brain biopsy with histopathologic examination is the criterion standard for the diagnosis of PML. Classic histopathologic changes of CPML and iPML have been described in previous sections. Sensitivity and specificity of brain biopsy are $64 \%-96 \%$ and $100 \%,{ }^{78}$ respectively, with estimated associated procedural complication in $2.9 \%$ and morbidity in $8.4 \%{ }^{79}$

If brain biopsy is not an option, as with debilitated or unwilling patients or inaccessible lesions, diagnosis of PML can be established by brain imaging or demonstration of JCV DNA by PCR of the CSF. Before the introduction of HAART, PCR for JCV DNA was very sensitive and specific with $72 \%-$ $92 \%$ sensitivity and $92 \%-100 \%$ specificity for the diagnosis of PML. ${ }^{80}$ Recently, however, it has become common to have negative PCR results in patients with AIDS with clinical and imaging presentations indistinguishable from those of PML. It may be possible that the immune restoration with antiretroviral therapy is associated with decreased viral replication and increased clearance of JCV DNA from the CSF. ${ }^{42}$ As a result of this, the sensitivity of PCR testing for JCV DNA has dropped to $58 \%{ }^{81,82}$

Imaging has become very important in the diagnosis of PML in the post-HAART era. In fact, most recently published diagnostic criteria classify PML as "definite PML" or "presumptive PML" on the basis of clinical presentation and imaging appearances with or without positive brain biopsy/PCR (Table 2).$^{38}$ Diagnosis of "definite PML" is considered when there are clinical and imaging findings consistent with PML plus evidence of JCV DNA in the CSF or presence of typical histopathologic changes with demonstration of JCV DNA/ protein in the infected cell by in situ techniques (Table 2). The diagnosis of "presumptive PML" is considered when there is evidence of typical imaging and clinical findings with no documentation of JCV (either brain biopsy or lumbar puncture was not performed or JCV DNA was not detected in the CSF).

The diagnosis of JCVGCN and JCE is confirmed by demonstration of JCV DNA/protein in the infected neuron by using double immunostaining methods.

\section{Imaging}

Imaging plays a pivotal role in diagnosis and follow-up of JCV infection. Physicians and patients alike are often reluctant to proceed with invasive brain biopsy. Furthermore, HAART reduces the diagnostic sensitivity of CSF PCR. Given the positive impact of treatment on survival times in these patients, understanding and recognizing the radiologic spectrum are important.

\section{cPML}

In the late 1980s, there were a few scattered case reports and small case series introducing MR imaging and CT features of PML. ${ }^{83-86}$ The classic CT finding was focal (or multifocal) nonenhancing white matter hypoattenuation without mass effect. Posterior fossa lesions cannot be evaluated properly by CT scan due to artifacts.

\section{MR Imaging}

MR imaging is the technique of choice for evaluation of PML. ${ }^{87}$ The imaging findings on conventional MR imaging are organized in regard to lesion distribution and characterization.

\section{Lesion Distribution}

Whiteman et $\mathrm{al}^{49}$ first described neuroimaging features of PML in a systematic way with clinical and pathologic correlation in 1993. Typically, PML is a confluent, bilateral but asymmetric, supratentorial white matter disease. However, it can be unilateral, and there may be a single lesion. ${ }^{49,88} \mathrm{CNS}$ involvement can be categorized in the following manner.

\section{White Matter Lesions}

Supratentorial. Because JCV has tropism to oligodendrocytes, any area of the brain may be affected. Asymmetric multifocal bilateral confluent supratentorial lobar white matter involvement is the most common manifestation. ${ }^{49,88}$ However, there may be only 1 lesion restricted to subcortical Ufibers, ${ }^{89,90}$ and this may be mistaken for stroke. ${ }^{91}$ The parietal lobe is most commonly involved, followed by the frontal lobe. Supratentorial lesions typically involve subcortical white matter with a scalloped appearance. ${ }^{92}$ Centrum semiovale and periventricular white matter can also be involved. White matter involvement has been reported to start in the subcortical regions, the site of highest blood flow, and then to move into the deeper white matter in the centrum semiovale and periventricular regions. ${ }^{93}$ Internal capsule, external capsule, and corpus callosum involvement are less common. Figure 1 demonstrates an example of a typical supratentorial cPML lesion.

Infratentorial. White matter of the posterior fossa is the next most common area of involvement. ${ }^{49,88}$ Typically the disease involves the middle cerebellar peduncle and adjacent pons and cerebellum. In an internal case review at our institution, all 9 patients with posterior fossa involvement had predominantly middle cerebellar peduncle involvement associated with adjacent cerebellum and/or pontine involvement. Pontine lesions may extend to the midbrain and/or medulla. Isolated cerebellar white matter or isolated medullary involvement is less common. Figure 2 demonstrates a typical infratentorial cPML lesion.

Spinal Cord. Spinal cord involvement in PML is exceedingly rare. There are only a handful of autopsy reports of the 


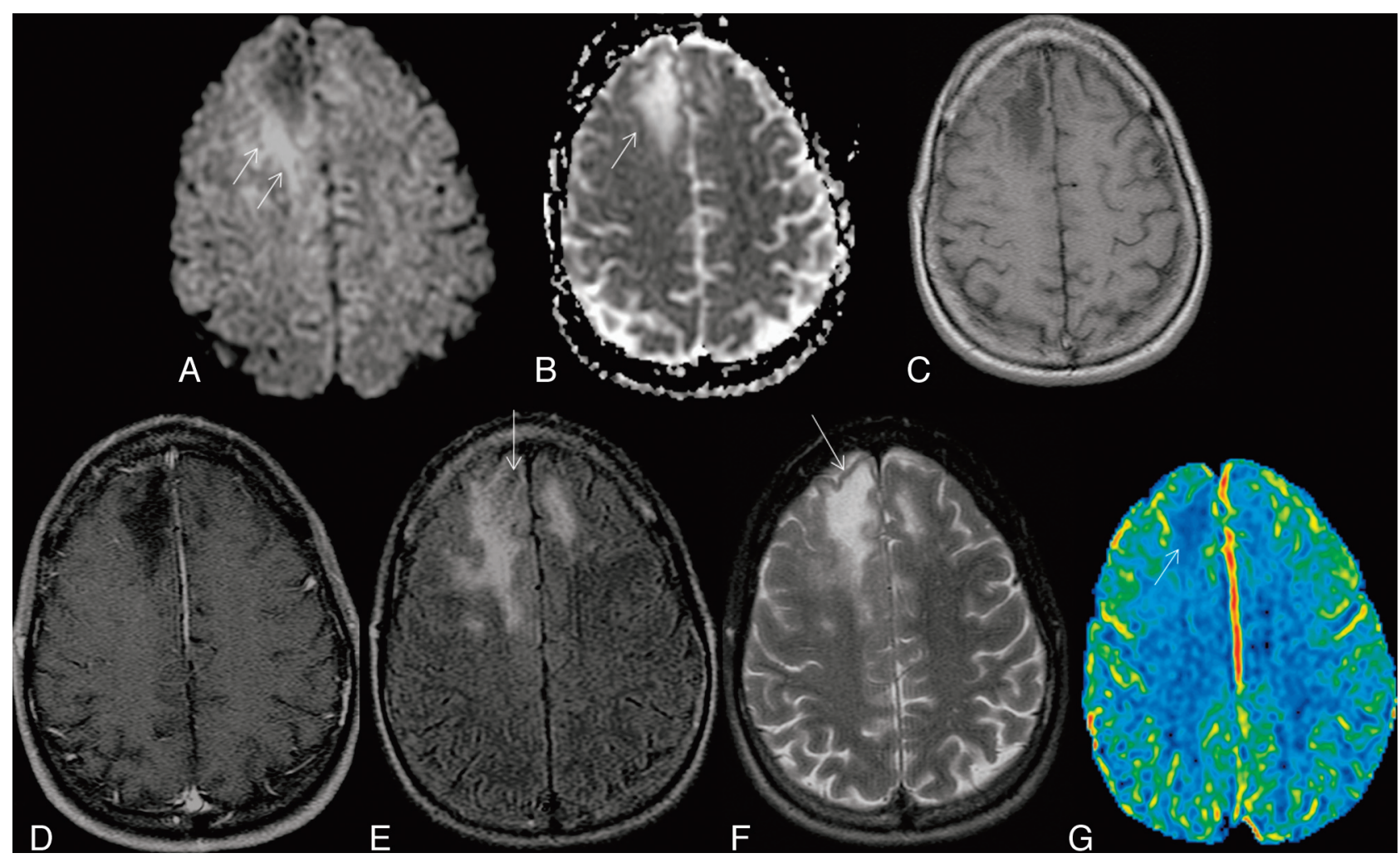

Fig 1. Typical supratentorial right frontal $\mathrm{CPML}$ in an HIV-positive patient. $A, \mathrm{On} \mathrm{DWI}$, the lesion shows typical restricted diffusion along the advancing edge posteriorly (arrows) and facilitated diffusion centrally. $B, O n$ the ADC map, ADC value is low at the posterior advancing edge (arrow) and high at the center of the lesion. $C$, The lesion typically involves the subcortical U-fiber and is hypointense (relative to gray matter) on the T1-weighted sequence. Note the absence of mass effect from this moderate-sized lesion. $D$, There is no enhancement of the lesion on the postcontrast T1-weighted sequence. $E$, On the FLAIR sequence, there is hyperintensity in most parts of the lesion. Note the inversion of the FLAIR high signal anteriorly (arrow) due to intralesional cystic change. F, On the T2-weighted sequence, the entire lesion is hyperintense. Note the adjacent anterior cortex is relatively spared (arrow). G, On perfusion imaging, cerebral blood volume of the lesion is lower (arrow) than that of the contralateral white matter.

spinal cord PML. ${ }^{94,95}$ As in the brain, spinal cord PML is typically limited to white matter tracts. Takeda et $\mathrm{al}^{94}$ described involvement of lateral and anterior columns of all 26 spinal segments in a patient with lymphocytopenia. To date, to our knowledge, there is no reported imaging of spinal cord PML.

\section{Gray Matter Lesions}

PML may involve gray matter as well. The thalamus is the most common area, followed by the basal ganglia. ${ }^{49,88}$ Usually gray matter lesions are associated with white matter involvement in almost all cases. Vary rarely, PML lesions can be isolated to the gray matter. ${ }^{96,97}$

\section{Lesion Location}

In the supratentorial type, lesions are typically limited to subcortical U-fibers surrounded by uninvolved cortical tissue. ${ }^{93}$ Confinement within subcortical U-fiber regions is considered to be a characteristic finding of PML and is used to differentiate PML lesions from HIV encephalopathy and other white matter diseases. ${ }^{93}$ Unlike other white matter diseases, PML lesions usually spare periventricular or deep white matter. However, with disease progression, adjacent white matter may be involved as well.

In the infratentorial type, lesions are classically located in the middle cerebellar peduncles, frequently extending to adjacent pons and/or cerebellum. In advanced disease, lesions can extend to the midbrain above and the medulla below.

\section{Imaging Appearances}

PML lesions are characteristically hypointense on T1. This low $\mathrm{T} 1$ signal intensity is considered a differentiating feature from HIV encephalopathy. ${ }^{98}$ With the initiation of HAART and with disease progression, there is an even further dramatic drop of T1 signal intensity. ${ }^{82,86}$ Less commonly, lesions may be $\mathrm{T} 1$ isointense. ${ }^{88}$ In some of the cPML lesions, there may be an incomplete hyperintense rim on precontrast T1-weighted sequences (as demonstrated in Fig 3 ) at the advancing edge. We saw this sign in 4 of our 15 patients. The exact histopathologic correlate of this has not been established. Cinque et $\mathrm{al}^{38}$ described the frequent presence of foamy (lipid laden) macrophages, in response to myelin breakdown. T1 hyperintensity in the advancing edge of some cPML lesions may be attributed to the presence of these macrophages (Figs 1 and 6). Because the presence of little or no inflammation is the classic histopathologic finding of PML, there is no breach of blood-brain barrier and the lesions typically do not enhance.

On T2-weighted sequences, lesions appear hyperintense to the cortex. Hyperintensity is seen within the lesion and also in the adjacent white matter, which is more prominent on FLAIR. On T2-weighted sequences, the demarcation of the lesion margin from the adjacent uninvolved gray matter is clearly seen (Fig 1). If PML progresses, smaller lesions coalesce, as seen in Fig 4. With progression or involution of a lesion, the central area becomes necrotic and appears hyperintense on T2 and is often attenuated on FLAIR sequences 


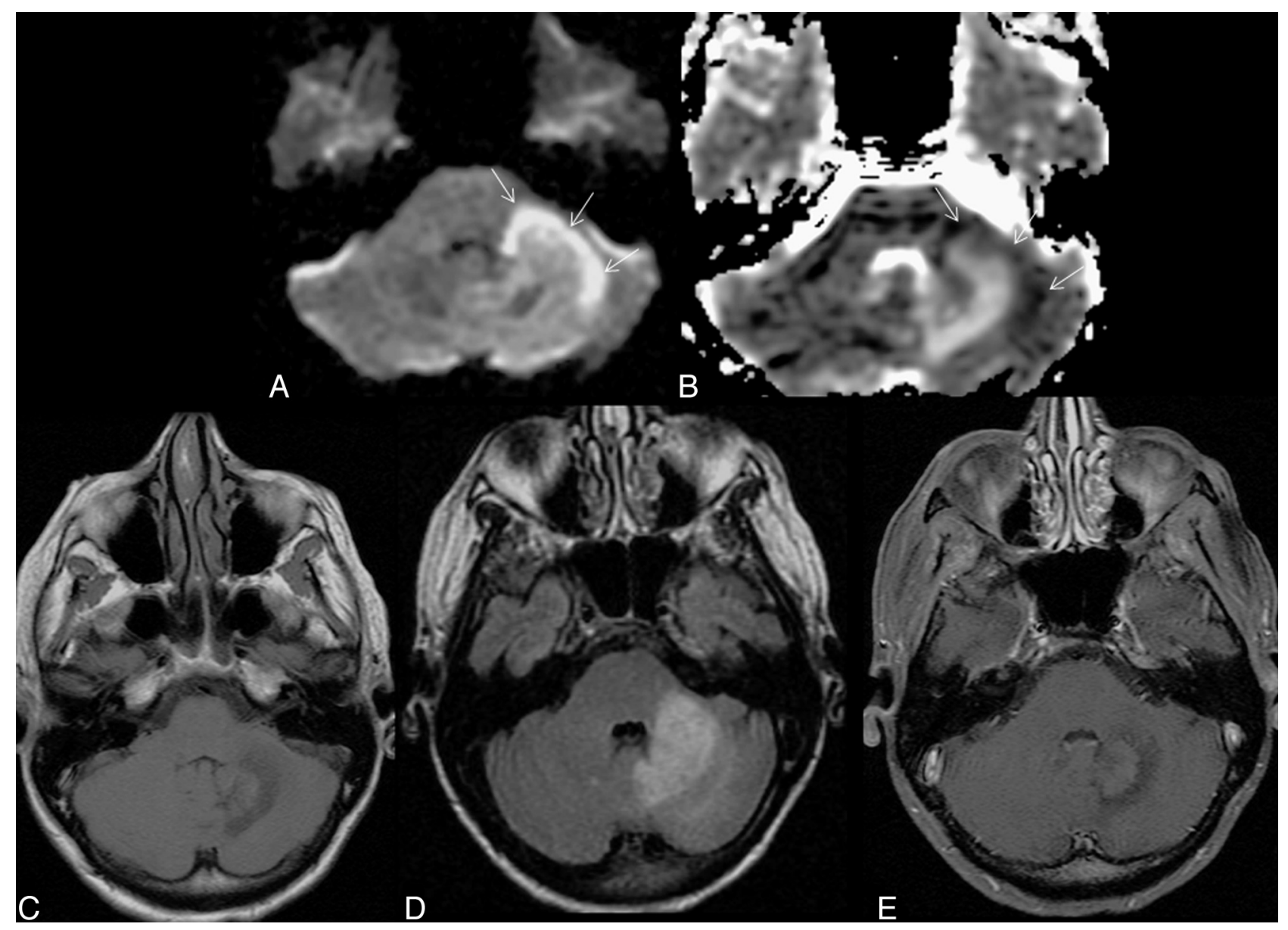

Fig 2. Typical infratentorial $c P M L$ in another HIV-positive patient classically involving the middle cerebellar peduncle (left). $A$ and $B$, This lesion also has diffusion restriction at the anterolateral advancing edge (high DWI signal intensity and low ADC value, arrows) and diffusion facilitation at the center as evidenced by the DWI (A) and the ADC map (B). $C$ and $D$, The lesion shows typical hypointensity on the T1-weighted sequence $(C)$ and hyperintensity on FLAIR $(D)$. Note, there are no mass effect. There is no enhancement in the postcontrast T1-weighted sequence $(E)$.
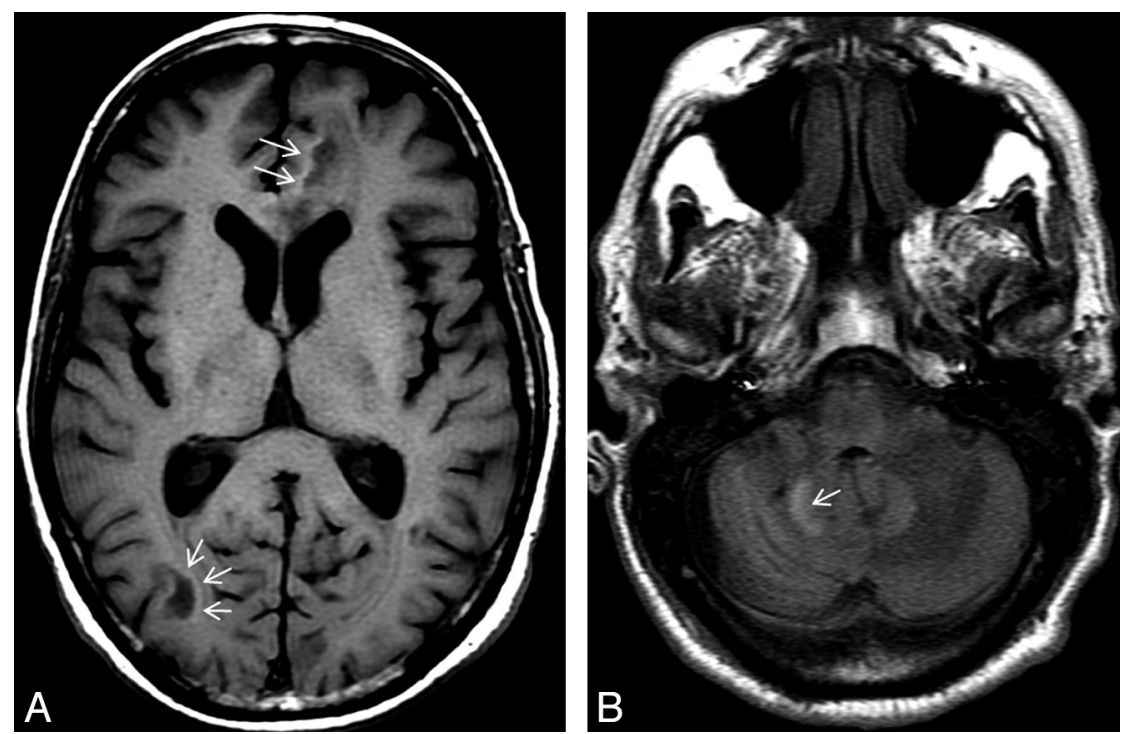

Fig 3. There is an incomplete rim of $\mathrm{T} 1$ hyperintensity (arrows) at the advancing edges of the supratentorial $(A)$ and infratentorial $(B) \mathrm{CPML}$ lesions.

(Figs 1 and 6). In some cases, there may be microcysts at the center of an active lesion on T2-weighted sequences (Fig 5). We have seen microcysts in 6 of our 15 patients with cPML.

Another typical imaging finding is absence of atrophy in the active stage.
Imaging of PML in Patients with MS

As briefly mentioned previously, PML can occur in MS patients treated with natalizumab. It is very difficult to differentiate a new PML lesion from an MS plaque in patients treated with natalizumab. A guideline for MR imaging characteriza- 

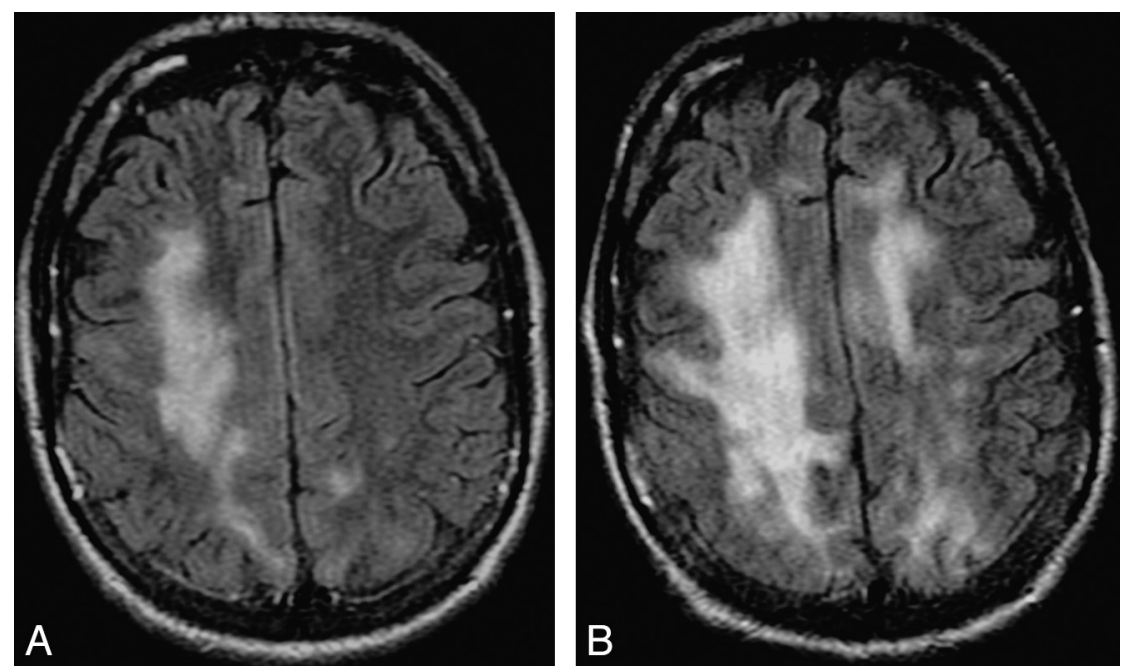

Fig 4. Progression of cPML. $A$ and $B$, These FLAIR images, 4 months apart, from an HIV-positive patient with $\mathrm{CPML}$ demonstrate typical progression of the supratentorial white matter FLAIR hyperintensity.

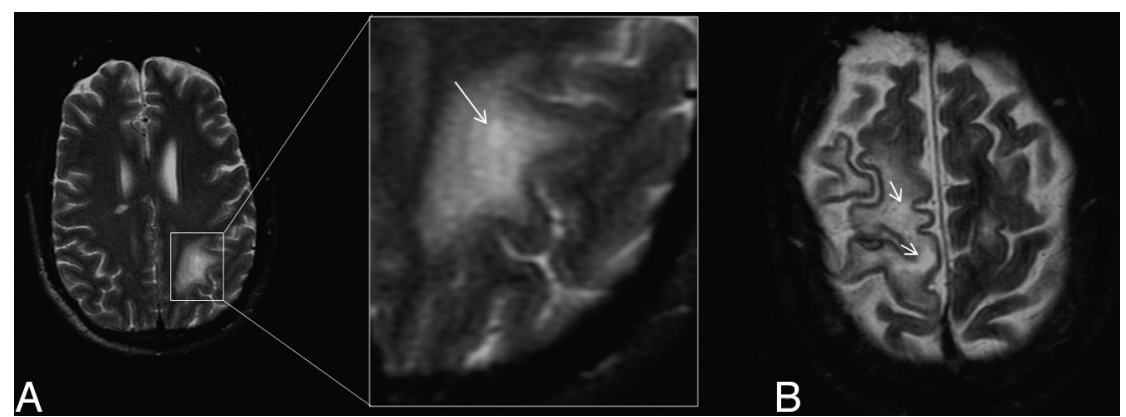

Fig 5. $A$, Intralesional microcyst on T2-weighted sequence on the left parietal $\mathrm{CPML}$ lesion in an HIV-positive patient, zoomed up in the inset. The arrow points to a microcyst. $B$, There are 2 intralesional microcysts (arrows) in this right fronto-parietal cPML lesion in another HIV-positive patient.

tion of new PML lesions in patients with MS was proposed by Yousry et al. ${ }^{99}$ According to this proposed guideline, the diagnosis of confirmed PML is entertained if all of the 3 following criteria are met:

1) Progressive clinical disease.

2) Typical MR imaging findings.

3) Demonstration of JCV DNA in the CSF.

Features favoring PML over MS (as proposed by Yousry et $\mathrm{al}^{99}$ ) are the following:

1) Diffuse subcortical rather than periventricular white matter involvement; frequent involvement of posterior fossa.

2) Irregular ill-defined infiltrating edge confined to the white matter.

3) Persistent progression of the lesion confined within the white matter tract.

4) No mass effect even in large lesions.

5) Diffuse increased T2 signal intensity; recently involved areas more $\mathrm{T} 2$ hyperintense than the old areas.

6) Initially iso- to hypointense with an incremental drop of T1 signal intensity with time; signal intensity never returning to normal.

7) Typically no enhancement, even in large lesions.

\section{Atypical Findings}

Rarely, lesions can spread from 1 lobe to the other through the corpus callosum, mimicking lymphoma or glioblastoma. ${ }^{88,100}$

\section{Diffusion Imaging}

In PML, the appearance on DWI varies according to the disease stage. ${ }^{101}$ In new active lesions, there is a rim of diffusion restriction at the advancing edge and a central core of facili- tated diffusion (Fig $1 A,-B) .{ }^{101,102}$ The rim is usually incomplete and signifies active infection. ${ }^{38}$ Histopathologically, this advancing edge correlates with large swollen oligodendrocytes, enlarged "bizarre astrocytes" with numerous large processes, and infiltration of foamy macrophages. ${ }^{38,49,101}$ This cellular enlargement constricts the extracellular space, the space of maximum Brownian motion of water. Diffusion restriction at the margin can be either due to constricted extracellular space ${ }^{103-105}$ or enlarged cells per se due to entrapment of water in motion-restricted intracellular space. ${ }^{106}$ In old "burnt out" lesions after therapy or at the center of a large lesion, there is facilitated diffusion due to disorganized cellular architecture, increased extracellular space secondary to dead oligodendrocytes, macrophage action, and astrocytic reparative responses. $^{101,107}$

Diffusion tensor imaging also has an important role in the evaluation of PML. Fractional anisotropy, which reflects the organized architecture of the white matter, decreases in PML, suggesting disorganization of the white matter structure. In fact, fractional anisotropy values may decrease in much earlier stages of the disease, when no lesion is evident on conventional and DWI. ${ }^{107}$ Diffusion tensor imaging parameters also have shown disorganized cellular architecture at the center of a large confluent lesion. ${ }^{108}$

\section{Magnetization Transfer Imaging}

Dousset et al ${ }^{109,110}$ noted that due to profound demyelination, there is a very low MTR (22\%) in PML lesions compared with the normal white matter (47\%) of volunteers. The authors also documented an incremental fall of MTR with disease progression, due to increasing demyelination. 

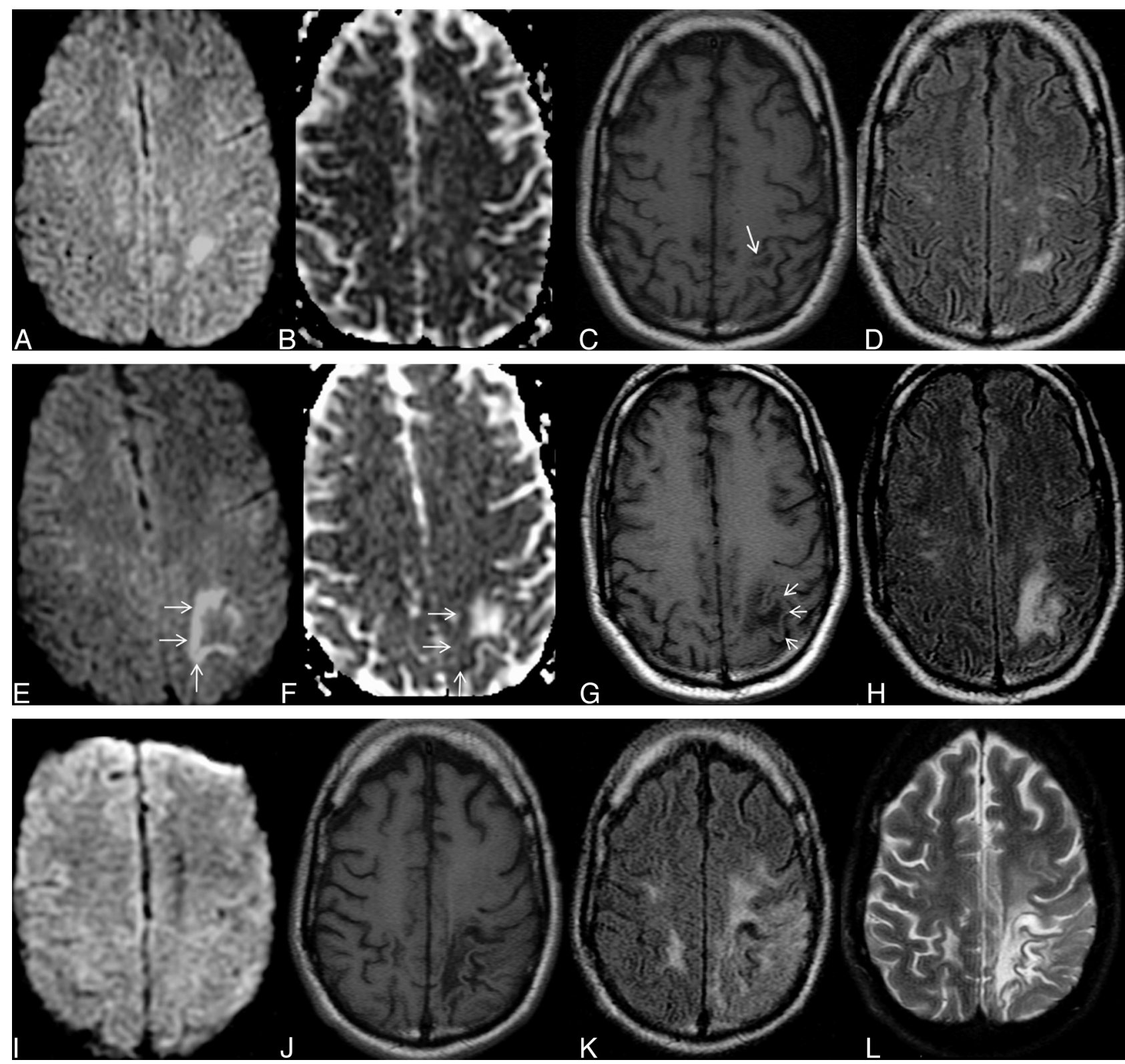

Fig 6. Typical disease course of cPML in an HIV-positive patient receiving HAART. Top panel, a set of images at presentation with focal diffusion restriction ( $A$ and $B$ ) and very subtle but typical hypointensity on $\mathrm{T} 1(C)$ and hyperintensity on FLAIR $(D)$. This initial study was confused with acute subcortical infarction. Middle panel, a set of images 1 month after the initial presentation. No HAART was administered before this scanning. Now the lesion has enlarged in size with typical diffusion restriction (arrows) at the medial and posterior advancing edges $(E$ and $A$. Now the T1 hypointensity is more obvious $(G)$. The adjacent cortex is not involved (arrows). Typically the lesion is hyperintense on FLAIR ( $H$ ). Bottom panel, a set of images 19 months after initial presentation. The patient received HAART for 18 months. Now there is no diffusion restriction ( $)$. On the T1-weighted sequence ( $)$, there is profound T1 hypointensity associated with new/progressive atrophy. There is FLAIR hyperintensity in the adjacent areas. However, the main lesion is not hyperintense on FLAIR ( $K$ ). On T2 ( $L$ ), the lesion itself is very hyperintense compared with the adjacent white matter, suggesting cystic encephalomalacia. Note that the adjacent cortical architecture is preserved.

\section{Spectroscopy}

Proton MR spectroscopy interrogates the chemical milieu of the neuronal microenvironment. In normal MR spectra, there are notable peaks: a prominent NAA peak as a marker for neuron and axon viability, a prominent choline peak (principally due to phosphatidyl choline) due to membrane constituents, and a Cr peak (principally due to creatine phosphate, which plays a role in maintaining energy-dependent systems in brain cells). ${ }^{111}$ Because the $\mathrm{Cr}$ peak remains fairly stable even in the face of disease, it may be used as an internal control. ${ }^{112}$ An additional peak may be present from lactate, due to inflammation or neuronal mitochondrial dysfunction or related to active anaerobic glycolytic metabolism. ${ }^{113}$ If a short
TE acquisition is used, it is possible to observe the mIns peak. ${ }^{113}$ In the brain, mIns is synthesized primarily in glial tissue. ${ }^{114}$ mIns is considered to be a glial marker, and an increase in its content is believed to represent glial proliferation or an increase in glial cell size. Because both processes may occur in brain inflammation, an increase in mIns may be a surrogate marker for inflammation in the brain. ${ }^{115}$

In the early stage of HIV infection, when clinical symptoms are absent or mild, NAA/Cr is unchanged (92\%-98\% of normal value). ${ }^{116-119}$ With the development of the AIDS complex, NAA/Cr decreases $\left(62 \%-84 \%\right.$ of normal value). ${ }^{116-119}$ The metabolic abnormalities increase proportionally with the severity of the disease. ${ }^{119}$ 

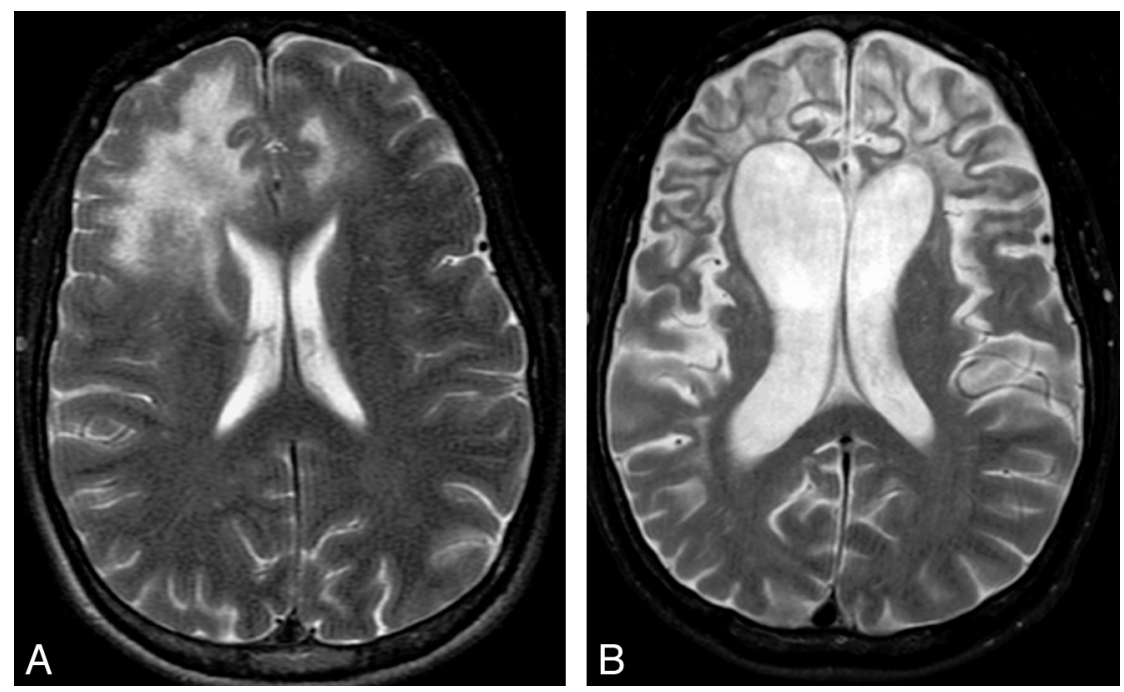

Fig 7. Sequel of CPML. $A$ and $B$, The 2 T2-weighted sequences, 16 months apart, from an HIV-positive patient demonstrate prominent brain atrophy with dilation of the ventricles and prominence of the sulci. Even at this advanced stage, there is minimal cortical involvement.

In PML, there is substantial decrease of the NAA peak to the contralateral NAA value, whether measured in relation to Cr or by absolute quantification. ${ }^{120}$ This may signify neuronal loss in the PML lesions. ${ }^{113}$ The choline peak is elevated, perhaps reflecting myelin destruction. ${ }^{113,120}$ The mIns peak may be normal or significantly elevated compared with the contralateral normal-appearing white matter. The level of mIns depends upon the stage of the disease. In early and active stage, there is increased level of mIns that gradually decreases to normal level in late quiescent stage. ${ }^{120}$ Elevation of the mIns/Cr ratio, which signifies local glial-only proliferation secondary to inflammation, has recently been described as a prognostic marker of the disease. In acute lesions, a significantly increased $\mathrm{mIns} / \mathrm{Cr}$ ratio is associated with increased survival time probably due to more intense inflammation that hinders PML disease progression. ${ }^{115}$

With this explanation, it is possible that the mIns peak may also be elevated in PML-IRIS because of the associated intense inflammation. To date, to our knowledge, there is no available literature on the spectroscopic appearance of PML-IRIS.

\section{Perfusion Imaging}

Histopathologically, PML lesions are not vascular. We obtained perfusion imaging only in 2 patients with cPML. As expected, in both patients, CPML lesions showed lower cerebral blood volume compared to the contralateral normal appearing white matter (Fig 1).

\section{Angiography}

Most PML lesions are angiographically negative because there is little or no inflammation. However, Nelson et $\mathrm{al}^{121}$ described pathologic parenchymal blush and arteriovenous shunting in 4 of the 6 patients of their series, which on histopathology turned out to be due to increased small vessel density and "robust inflammatory" changes. The authors concluded that this increased microvascular density was due to neoangiogenesis versus accelerated contrast passage secondary to altered microvascular tone in the presence of different inflammatory kinins. The latter mechanism is a more likely explanation for the angiographic abnormality because all 4 patients had features of iPML on cross-sectional imaging (ie, either mass effect or contrast enhancement).

\section{Nuclear Imaging}

Because cPML lesions are pathologically neither inflammatory nor neoplastic, they are not identified in the nuclear medicine studies. In a study of 6 patients, Iranzo et a ${ }^{122}$ reported no uptake in any of the patients with positive MR imaging signs. In the study of Lee et al, ${ }^{123} 1$ of the 3 patients with PML did not show any uptake either in the thallium 201 or the gallium 67 scan. However, in this study, 2 of the 3 patients showed both thallium 201 and gallium 67 intake. Although MR imaging or histopathologic features of these 2 patients were not mentioned in the article, probably these 2 patients had iPML. Port et al ${ }^{124}$ described a patient with PML with uptake of thallium 201, contrast enhancement on the MR imaging, and numerous macrophage infiltrations on histopathology. Although the term "iPML" was not introduced at that time, the authors concluded that the uptake of thallium 201 in that patient was due to an "inflammatory reaction."

Theoretically, all cPML should have negative nuclear scintigraphy findings, and all iPML lesions should have positive nuclear scintigraphy findings. A systematic study is needed to prove this hypothesis.

\section{Signs of Disease Progression}

Increasing confluence and extent of white matter lesions, increasing cortical atrophy, and incremental drop of T1 signal intensity signify disease progression and poor prognosis. ${ }^{88}$ Figure 6 demonstrates the typical progression of the disease with time even with use of HAART. In the late stage of the disease, there is generalized atrophy and diffuse white matter involvement (Fig 7). Associated HIV encephalopathy may augment the process.

\section{Can Imaging Monitor Treatment?}

According to Thurnher et al, ${ }^{92}$ differentiation between treatment responders versus nonresponders can be made with FLAIR signal intensity; findings of progressively decreasing T1 and FLAIR signal intensity on follow-up imaging indicate the burnt out part of the PML lesions due to leukomalacia and associated atrophy (bottom panel of Fig 6). On the other hand, increasing FLAIR intensity and progressive T1 hypointensity indicate progressive disease and are poor prognostic signs. ${ }^{109}$ In an isolated case report, Usiskin et $\mathrm{al}^{108}$ documented resto- 
ration of white matter anisotropy in a pathologically proved PML case in response to HAART by using high-b-value DWI.

\section{Can Imaging Predict Prognosis?}

In a pathologically proved large series, Post et $\mathrm{al}^{88}$ found no correlation between lesion size, lesion location, signal intensity, brain atrophy, or hydrocephalus and patient survival. However, there was significant positive correlation between risk of death and mass effect at baseline imaging. Also there was a 2-fold increase in risk of death in patients with basal ganglia gray matter involvement. In this study, there was a trend toward increasing survival in patients with multiple discrete lesions versus large confluent lesions. In a comparative study between short-term survivors and long-term survivors, Thurnher et $\mathrm{al}^{92}$ noticed that extensive brain involvement was associated with longer survival time. Increased mIns/Cr ratio in the lesion also signifies favorable prognosis. ${ }^{115}$

\section{iPML}

The imaging manifestation of iPML is exactly like that of cPML except that the lesion has additional peripheral enhancement and/or mass effect due to inflammation. Rarely, the contrast enhancement is so subtle that it may not be identified on a regular spin-echo T1 sequence and can be detected only by using a magnetization transfer imaging pulse on $\mathrm{T} 1$ sequences. Due to an inflammatory infiltrate, these lesions may have high intake in nuclear scintigraphy scanning.

\section{JCVGCN}

In $\mathrm{JCVGCN}{ }^{55}$ there is isolated involvement of the internal granular cell layer of the cerebellum without white matter involvement. In the early stage of the disease, there is no specific MR finding. In later stages, there is isolated cerebellar atrophy followed by increased T2 signal intensity.

\section{JCM}

There is no specific MR imaging finding of JCM.

\section{JCE}

Unlike PML, lesions in JCE are initially restricted to hemispheric gray matter with extension to the subcortical white matter with progression of the disease. Like cPML, lesions do not enhance on contrast. ${ }^{58}$

\section{Treatment}

There is no specific treatment for JCV infection. In HIV-infected patients, optimization of HAART is the best therapeutic choice. HAART may stabilize the clinical and imaging manifestations of the disease in $\leq 50 \%-60 \%$ of HIV-positive patients with PML. ${ }^{38}$ In HIV-negative patients, removal of the cause of immunosuppression (steroids, calcineurin inhibitors in transplant patients, natalizumab etc) as much as clinically allowable is the treatment of choice. ${ }^{125}$ A number of specific drugs against JCV such as cytarabine, cidofovir, and topotecan were used in multiple clinical trials. All these investigational drugs showed either no clinical benefit or possible benefit at the expense of high toxicity. ${ }^{38}$ In patients with PML-IRIS, steroid should be started in patients with inflammation-induced worsening of symptoms or signs. ${ }^{38}$

\section{Conclusions}

It is now clear that the term "PML" fails in defining the disease spectrum of JCV infection. JCV infection may not have a progressive course, may not be multifocal, and may not be contained within the white matter. The appropriate terminology should be based on histopathology and/or imaging appearances. The term "PML" alone should be avoided in favor of the more descriptive terms cPML or iPML, on the basis of the imaging and or histopathologic appearances. Also, neurotropic manifestations of JCV infection (JCVGCN, JCE, etc) should not be confused with either type of PML.

\section{References}

1. Padgett BL, Walker DL, Zu Rhein GM, et al. Cultivation of papova-like virus from human brain with progressive multifocal leucoencephalopathy. Lancet 1971;29:1257-60

2. Åström KE, Mancall EL, Richardson EP. Progressive multifocal leukoencephalopathy: a hitherto unrecognized complication of chronic lymphatic leukaemia and Hodgkin's disease. Brain 1958;81:93-111

3. Hartman EA, Huang D. Update on PML: lessons from the HIV uninfected and new insights in pathogenesis and treatment. Curr Hiv/AIDS Rep 2008; 5:112-19

4. Bofill-Mas S, Formiga-Cruz M, Clemente-Casares P, et al. Potential transmission of human polyomaviruses through the gastrointestinal tract after exposure to virions or viral DNA. J Virol 2001;75:10290-99

5. Monaco MC, Jensen PN, Hou J, et al. Detection of JC virus DNA in human tonsil tissue: evidence for site of initial viral infection. J Virol 1998; 72:9918-23

6. Gheuens S, Pierone G, Peeters P, et al. Progressive multifocal leukoencephalopathy in individuals with minimal or occult immunosuppression. J Neurol Neurosurg Psychiatry 2010;81:247-54

7. Bienaime A, Colson P, Moreau J, et al. Progressive multifocal leukoencephalopathy in HIV-2-infected patient. AIDS 2006;20:1342-43

8. Stoner GL, Agostini HT, Ryschkewitsch CF, et al. Detection of JC virus in two African cases of progressive multifocal leukoencephalopathy including identification of JCV type 3 in a Gambian AIDS patient. J Med Microbiol 1998; $47: 733-42$

9. d'Arminio Monforte A, Cinque P, Mocroft A, et al. Changing incidence of central nervous system diseases in the EuroSIDA cohort. Ann Neurol 2004;55:320-28

10. Lang W, Miklossy J, Deruaz JP, et al. Neuropathology of the acquired immune deficiency syndrome (AIDS): a report of 135 consecutive autopsy cases from Switzerland. Acta Neuropathol 1989;77:379-90

11. Cinque $P$, Vago L, Dahl H, et al. Polymerase chain reaction on cerebrospinal fluid for diagnosis of virus-associated opportunistic diseases of the central nervous system in HIV-infected patients. AIDS 1996;10:951-58

12. Falco V, Olmo M, del Saz SV, et al. Influence of HAART on the clinical course of HIV-1-infected patients with progressive multifocal leukoencephalopathy: results of an observational multicenter study. J Acquir Immune Defic Syndr 2008;49:26-31

13. Mocroft A, Sterne JA, Egger M, et al. Variable impact on mortality of AIDSdefining events diagnosed during combination antiretroviral therapy: no all AIDS-defining conditions are created equal. Clin Infect Dis 2009;48: $1138-51$

14. Lewden C, May T, Rosenthal E, et al. Changes in causes of death among adults infected by HIV between 2000 and 2005: the "Mortalite 2000 and 2005" surveys (ANRS EN19 and Mortavic). J Acquir Immune Defic Syndr 2008;48: 590-98

15. Garcia-Suarez J, deMiguel D, Krsnik I, et al. Changes in the natural history of progressive multifocal leukoencephalopathy in HIV-negative lymphoproliferative disorders: impact of novel therapies. Am J Hematol 2005;80:271-81

16. Shitrit D, Lev N, Bar-Gil-Shirit A, et al. Progressive multifocal leukoencephalopathy in transplant recipients. Transpl Int 2005; 17:658-65

17. Kharfan-Dabaja MA, Ayala E, Greene J, et al. Two cases of progressive multifocal leukoencephalopathy after allogenic hematopoietic cell transplantation and review of the literature. Bone Marrow Transplant 2007;39:101-07

18. Calabrese LH, Molloy ES, Huang D, et al. Progressive multifocal leukoencephalopathy in rheumatic diseases: evolving clinical and pathological patterns of disease. Arthritis Rheum 2007;56:2116-28

19. Hayashi Y, Kimura A, Kato S, et al. Progressive multifocal leukoencephalopathy and CD4+ T-lymphocytopenia in a patient with Sjögren syndrome. J Neurol Sci 2008;268:195-98

20. De Raedt S, Lacor P, Michotte A, et al. Progressive multifocal leukoencephalopathy as first manifestation of sarcoidosis. Clin Neurol Neurosurg 2008;110 $186-89$

21. Van Assche G, Van Ranst M, Sciot R, et al. Progressive multifocal leukoen- 
cephalopathy after natalizumab therapy for Crohn's disease. $N$ Engl J Med 2005;353:362-68

22. Kleinschmidt-DeMasters BK, Tyler KL. Progressive multifocal leukoencephalopathy complicating treatment with natalizumab and interferon beta-1a for multiple sclerosis. $N$ Engl J Med 2005;353:369-74

23. Langer-Gould A, Atlas SW, Green AJ, et al. Progressive multifocal leukoencephalopathy in a patient treated with natalizumab. N Engl J Med 2005;353: 375-81

24. Molloy ES, Calabrese LH. Therapy: targeted but not trouble-free-efalizumab and PML. Nat Rev Rheumatol 2009;5:418-19

25. Carson KR, Focosi D, Major EO, et al. Monoclonal antibody associated progressive multifocal leucoencephalopathy in patients treated with rituximab, natalizumab, and efalizumab: a review from the Research on Adverse Drug Events and Reports (RADAR) Project. Lancet Oncol 2009;10:816-24

26. Tyler KL. Emerging viral infections of the central nervous system: part 2 . Arch Neurol 2009;66:1065-74

27. US Food and Drug Administration. Information for healthcare professionals: rituximab (marketed as Rituxan). http://www.fda.gov/Drugs/DrugSafety/Post marketDrugSafetyInformationforPatientsandProviders/ucm126519.htm

28. Haider S, Nafziger D, Gutierrez JA, et al. Progressive multifocal leukoencephalopathy and idiopathic CD4+lymphocytopenia: a case report and review of reported cases. Clin Infect Dis 2000;31:E20-22

29. Chikezie PU, Grennberg AL. Idiopathic CD41 Tlymphocytopenia presenting as progressive multifocal leukoencephalopathy: case report. Clin Infect Dis $1997 ; 24: 526-27$

30. Iwase T, Kosei O, Katada E, et al. An unusual course of progressive multifocal leukoencephalopathy in a patient with idiopathic CD41 T lymphocytopenia. J Neurol Neurosurg Psychiatry 1998;64:788-91

31. Scotton PG, Vaglia A, Carniato A, et al. Progressive multifocal leukoencephalopathy in a patient with common variable immunodeficiency. Clin Infect Dis 1998;26:215-16

32. Narula S, LaRosa DF, Kamoun M, et al.. Progressive multifocal leukoencephalopathy in a patient with common variable immunodeficiency and abnormal CD8+ T-cell subset distribution. Ann Allergy Asthma Immunol 2007;98: 483-89

33. Goldmann C, Petry H, Frye S, et al. Molecular cloning and expression of major structural protein VP1 of the human polyomavirus JC virus: formation of virus-like particles useful for immunological and therapeutic studies. J Virol 1999;73:4465-69

34. Goldmann C, Stolte N, Nisslein T, et al. Packaging of small molecules into VP1-virus-like particles of the human polyomavirus JC virus. J Virol Methods 2000;90:85-90

35. Weber T. Progressive multifocal leukoencephalopathy. Neurol Clin 2008;26: 833-54

36. Lednicky JA, Vilchez RA, Keitel WA, et al. Polyomavirus JCV excretion and genotype analysis in $\mathrm{HIV}$-infected patients receiving highly active antiretroviral therapy. AIDS 2003;17:801-07

37. Tan CS, Dezube BJ, Bhargava P, et al. Detection of JC virus DNA and proteins in the bone marrow of HIV-positive and HIV-negative patients: implications for viral latency and neurotropic transformation. J Infect Dis 2009;199: 881-88

38. Cinque P, Koralnik IJ, Gerevini S, et al. Progressive multifocal leukoencephalopathy in HIV-1 infection. Lancet Infect Dis 2009;9:625-36

39. Jensen PN, Major EO. A classification scheme for human polyomavirus JCV variants based on the nucleotide sequence of the noncoding regulatory region. J Neurovirol 2001;7:280-87

40. Lima MA, Marzocchetti A, Autissier P, et al. Frequency and phenotype of JC virus-specific CD8 + T lymphocytes in the peripheral blood of patients with progressive multifocal leukoencephalopathy. J Virol 2007;81:3361-68

41. Berger JR. Progressive multifocal leukoencephalopathy in acquired immunodeficiency syndrome: explaining the high incidence and disproportionate frequency of the illness relative to other immunosuppressive conditions. J Neurovirol 2003;9:38-41

42. Cinque $\mathrm{P}$, Bossolasco S, Brambilla AM, et al. The effect of highly active antiretroviral therapy-induced immune reconstitution on development and outcome of progressive multifocal leukoencephalopathy: study of 43 cases with review of the literature. J Neurovirol 2003;9:73-80

43. Khanna N, Elzi L, Mueller NJ, et al. Incidence and outcome of progressive multifocal leukoencephalopathy over 20 years of the Swiss HIV Cohort Study. Clin Infect Dis 2009;48:1459-66

44. Gasnault J, Kahraman M, de Goer de Herve MG, et al. Critical role of JC virus-specific CD4 $\mathrm{T}$-cell responses in preventing progressive multifocal leukoencephalopathy. AIDS 2003;17:1443-49

45. Du Pasquier RA, Kuroda MJ, Zheng Y, et al. A prospective study demonstrates an association between JC virus-specific cytotoxic T lymphocytes and the early control of progressive multifocal leukoencephalopathy. Brain 2004; 127:1970-78

46. Giudici B, Vaz B, Bossolasco S, et al. Highly active antiretroviral therapy and progressive multifocal leukoencephalopathy: effects on cerebrospinal fluid markers of JC virus replication and immune response. Clin Infect Dis 2000; 30:95-99
47. Berger JR, Pall L, Lanska D, et al. Progressive multifocal leukoencephalopathy in patients with HIV infection. J Neurovirol 1998;4:59-68

48. Lima MA, Drislane FW, Koralnik IJ. Seizures and their outcome in progressive multifocal leukoencephalopathy. Neurology 2006;66:262-64

49. Whiteman ML, Post MJ, Berger JR, et al. Progressive multifocal leukoencephalopathy in 47 HIV-seropositive patients: neuroimaging with clinical and pathologic correlation. Radiology 1993;187:233-40

50. Richardson EP Jr. Progressive multifocal leukoencephalopathy. N Engl J Med 1961;265:815-23

51. Ng S, Tse VC, Rubinstein J, et al. Progressive multifocal leukoencephalopathy: unusual MR findings. J Comput Assist Tomogr 1995;19:302-05

52. Huang D, Cossoy M, Li M, et al. Inflammatory progressive multifocal leukoencephalopathy in human immunodeficiency virus-negative patients. Ann Neurol 2007;62:34-39

53. Miralles $\mathrm{P}$, Berenguer $\mathrm{J}$, Lacruz $\mathrm{C}$, et al. Inflammatory reactions in progressive multifocal leukoencephalopathy after highly active antiretroviral therapy. AIDS 2001;15:1900-02

54. Vendrely A, Bienvenu B, Gasnault J, et al. Fulminant inflammatory leukoencephalopathy associated with HAART-induced immune restoration in AIDS-related progressive multifocal leukoencephalopathy. Acta Neuropathol 2005;109:449-55

55. Koralnik IJ, Wüthrich C, Dang X, et al. JC virus granule cell neuronopathy: novel clinical syndrome distinct from progressive multifocal leukoencephalopathy. Ann Neurol 2005;57:576-80

56. Dang X, Koralnik IJ. A granule cell neuron-associated JC virus variant has a unique deletion in the VP1 gene. J Gen Virol 2006;87:2533-37

57. Blake K, Pillay D, Knowles W, et al. JC virus associated meningoencephalitis in an immunocompetent girl. Arch Dis Child 1992;67:956-57

58. Behzad-Behbahani A, Klapper PE, Vallely PJ, et al. BKV-DNA and JCV-DNA in CSF of patients with suspected meningitis or encephalitis. Infection 2003; 31:374-78

59. Viallard JF, Ellie E, Lazaro E, et al. JC virus meningitis in a patient with systemic lupus erythematosus. Lupus 2005;14:964-66

60. Wüthrich C, Dang X, Westmoreland S, et al. Fulminant JC virus encephalopathy with productive infection of cortical pyramidal neurons. Ann Neuro 2009;65:742-48

61. DeSimone JA, Pomerantz RJ, Babinchak TJ. Inflammatory reactions in HIV1-infected persons after initiation of highly active antiretroviral therapy. Ann Intern Med 2000;133:447-54

62. Shelburne SA, Montes M, Hamill RJ. Immune reconstitution inflammatory syndrome: more answers, more questions. J Antimicrob Chemother 2006;57: $167-70$

63. Shelburne SA, Visnegarwala F, Darcourt J, et al. Incidence and risk factors for immune reconstitution inflammatory syndrome during highly active antiretroviral therapy. AIDS 2005;19:399-406

64. Shelburne SA, Darcourt J, White AC, et al. The role of immune reconstitution inflammatory syndrome in AIDS related Cryptococcus neoformans disease in the era of highly active antiretroviral therapy. Clin Infect Dis 2005;40: 1049-52

65. Price $\mathrm{P}$, Morahan $\mathrm{G}$, Huang $\mathrm{D}$, et al. Polymorphisms in cytokine genes define subpopulations of HIV-1 patients who experienced immune restoration diseases. AIDS 2002;16:2043-47

66. Stoll M, Schmidt RE. Immune restoration inflammatory syndromes: apparently paradoxical clinical events after the initiation of HAART. Curr HIV/ AIDS Rep 2004;1:122-27

67. Robertson J, Meier M, Wall J, et al. Immune reconstitution syndrome in HIV validating a case definition and identifying clinical predictors in persons initiating antiretroviral therapy. Clin Infect Dis 2006;42:1639-46

68. Riedel DJ, Pardo CA, McArthur J, et al. Therapy insight: CNS manifestations of HIV-associated immune reconstitution inflammatory syndrome. Nat Clin Prac Neurol 2006;2:557-65

69. Huyst V, Lynen L, Bottieau E, et al. Immune reconstitution inflammatory syndrome in an HIV/TB co-infected patient four years after starting antiretroviral therapy. Acta Clin Belg 2007;62:126-29

70. Shelburne SA 3rd, Hamill RJ. The immune reconstitution inflammatory syndrome. AIDS Rev 2003;5:67-79

71. Venkataramana A, Pardo CA. Immune reconstitution inflammatory syndrome in the CNS of HIV-infected patients. Neurology 2006;67:383-88

72. D'Amico R, Sarkar S, Yusuff J, et al. Immune reconstitution after poten antiretroviral therapy in AIDS patients with progressive multifocal leukoencephalopathy. Scand J Infect Dis 2007;39:347-50

73. Manabe Y, Campbell JD, Sydnor E, et al. Immune reconstitution inflammatory syndrome: risk factors and treatment implications. J Acquir Immune Defic Syndr 2007;46:456-62

74. Broom J, Woods M 2nd, Allworth A. Immune reconstitution inflammatory syndrome producing atypical presentations of cryptococcal meningitis: case report and a review of immune reconstitution-associated cryptococcal infections. Scand J Infect Dis 2006;38:219-2

75. Cinque P, Pierotti C, Vigano MG, et al. The good and evil of HAART in HIVrelated progressive multifocal leukoencephalopathy. J Neurovirol 2001;7: $358-63$ 
76. French MA. HIV/AIDS: immune reconstitution inflammatory syndrome-a reappraisal. Clin Infect Dis 2009;48:101-07

77. Tan K, Roda R, Ostrow L, et al. PML-IRIS in patients with HIV infection: clinical manifestations and treatment with steroids. Neurology 2009;72: 1458-64

78. Koralnik IJ, Boden D, Mai VX, et al. JC virus DNA load in patients with and without progressive multifocal leukoencephalopathy. Neurology 1999;52: 253-60

79. Skolasky RL, Dal Pan GJ, Olivi A, et al. HIV-associated primary CNS morbidity and utility of brain biopsy. J Neurol Sci 1999;163:32-38

80. Cinque P, Scarpellini P, Vago L, et al. Diagnosis of central nervous system complications in HIV-infected patients: cerebrospinal fluid analysis by the polymerase chain reaction. AIDS 1997;11:1-17

81. Antinori A, Cingolani A, Lorenzini P, et al. Clinical epidemiology and survival of progressive multifocal leukoencephalopathy in the era of highly active antiretroviral therapy: data from the Italian Registry Investigative Neuro AIDS (IRINA). J Neurovirol 2003;9(suppl 1):47-53

82. Marzocchetti A, Di Giambenedetto S, Cingolani A, et al. Reduced rate of diagnostic positive detection of JC virus DNA in cerebrospinal fluid in cases of suspected progressive multifocal leukoencephalopathy in the era of potent antiretroviral therapy. J Clin Microbiol 2005;43:4175-77

83. Post MJ, Sheldon JJ, Hensley CT, et al. Central nervous system disease in acquired immunodeficiency syndrome: prospective correlation using CT, MR imaging, and pathologic studies. Radiology 1986;158:141-48

84. Post MJ, Tate LG, Quencer RM, et al. CT, MR, and pathology in HIV encephalitis and meningitis. AJNR Am J Neuroradiol 1988;9:469-76

85. Cuilleux MH, Steiner RE, Young IR. MR imaging in progressive multifocal leukoencephalopathy. AJNR Am J Neuroradiol 1986;7:1033-35

86. Mark AS, Atlas SW. Progressive multifocal leukoencephalopathy in patients with AIDS: appearance on MR images. Radiology 1989;173:517-21

87. Thurnher MM, Thurnher SA, Muhlbauer B, et al. Progressive multifocal leukoencephalopathy in AIDS: initial and follow-up CT and MRI. Neuroradiology 1997;39:611-18

88. Post MJ, Yiannoutsos C, Simpson D, et al. Progressive multifocal leukoencephalopathy in AIDS: are there any MR findings useful to patient management and predictive of patient survival? AJNR Am J Neuroradiol 1999;20: 1896-906

89. Gray F, Geny C, Lescs MC, et al. AIDS-related progressive multifocal leukoencephalopathy limited to U fibers, responsible for subacute encephalopathy with normal CT scan findings [in French]. Arch Anat Cytol Pathol 1992; 40:132-37

90. Trotot PM, Vazeux R, Yamashita HK, et al. MRI pattern of progressive multifocal leukoencephalopathy (PML) in AIDS: pathological correlations. J Neuroradiol 1990;17:233-54

91. Koralnik IJ, Schellingerhout D, Frosch MP. Case records of the Massachusetts General Hospital: weekly clinicopathological exercises-case 14-2004. a 66year-old man with progressive neurologic deficits. N Engl J Med 2004;350: 1882-93

92. Thurnher MM, Post MJ, Rieger A, et al. Initial and follow-up MR imaging findings in AIDS-related progressive multifocal leukoencephalopathy treated with highly active antiretroviral therapy. AJNR Am J Neuroradiol 2001;22:977-84

93. Major EO, Ault GS. Progressive multifocal leukoencephalopathy: clinical and laboratory observations on a viral induced demyelinating disease in the immunodeficient patient. Curr Opin Neurol 1995;8:184-90

94. Takeda S, Yamazaki K, Miyakawa T, et al. Progressive multifocal leukoencephalopathy showing extensive spinal cord involvement in a patient with lymphocytopenia. Neuropathology 2009;29:485-93

95. Bernal-Cano F, Joseph JT, Koralnik IJ. Spinal cord lesions of progressive multifocal leukoencephalopathy in an acquired immunodeficiency syndrome patient. J Neurovirol 2007;13:474-76

96. Sweeney BJ, Manji H, Miller RF, et al. Cortical and subcortical JC virus infection: two unusual cases of AIDS associated progressive multifocal leukoencephalopathy. J Neurol Neurosurg Psychiatry 1994;57:994-97

97. Bienfait HP, Louwerse ES, Portegies P, et al. Progressive multifocal leukoencephalopathy presenting as a solitary gray matter lesion. J Neurol 1998;245: $557-58$

98. Sarrazin JL, Soulie D, Derosier C, et al. MRI patterns of progressive multifocal leukoencephalopathy. J Neuroradiol 1995;22:172-79

99. Yousry TA, Major EO, Ryschkewitsch C, et al. Evaluation of patients treated with natalizumab for progressive multifocal leukoencephalopathy. $N$ Engl J Med 2006;354:924-33

100. Wheeler AL, Truwit CL, Kleinschimdt-DeMasters BK, et al. Progressive mul- tifocal leukoencephalopathy: contrast enhancement on CT scans and MR images. AJR Am J Roentgenol 1993;161:1049-51

101. Bergui M, Bradac GB, Oguz KK, et al. Progressive multifocal leukoencephalopathy: diffusion-weighted imaging and pathological correlations. Neuroradiology 2004;46:22-25

102. Henderson RD, Smith MG, Mowat P, et al. Progressive multifocal leukoencephalopathy. Neurology 2002;58:1825

103. Norris DG, Niendorf T, Hoehn-Berlage M, et al. Incidence of apparent restricted diffusion in three different models of cerebral infarction. Magn Reson Imaging 1994;12:1175-82

104. Verheul HB, Balazs R, Berkelbach van der Sprenkel JW, et al. Comparison of diffusion-weighted MRI with changes in cell volume in a rat model of brain injury. NMR Biomed 1994;7:96-100

105. Qiao M, Malisza KL, Del Bigio MR, et al. Transient hypoxia-ischemia in rats changes in diffusion-sensitive MR imaging findings, extracellular space, and $\mathrm{Na}+-\mathrm{K}+$-adenosinetriphosphatase and cytochrome oxidase activity. Radiology 2002;223:65-75

106. Moseley ME, Kucharczyk J, Asgari HS, et al. Anisotropy in diffusion-weighted MRI. Magn Reson Med 1991;19:321-26

107. Huisman TA, Boltshauser E, Martin E, et al. Diffusion tensor imaging in progressive multifocal leukoencephalopathy: early predictor for demyelination? AJNR Am J Neuroradiol 2005;26:2153-56

108. Usiskin SI, Bainbridge A, Miller RF, et al. Progressive multifocal leukoencephalopathy: serial high-b-value diffusion-weighted MR imaging and apparent diffusion coefficient measurements to assess response to highly active antiretroviral therapy. AJNR Am J Neuroradiol 2007;28:285-86

109. Dousset V, Armand JP, Lacoste D, et al. Magnetization transfer study of HIV encephalitis and progressive multifocal leukoencephalopathy: Groupe d'Epidemiologie Clinique du SIDA en Aquitaine. AJNR Am J Neuroradiol 1997;18:895-901

110. Dousset V, Armand J-P, Huot P, et al. Magnetization transfer imaging in AIDS-related brain diseases. Neuroimaging Clin N Am 1997;7:447-60

111. Kreis R, Ernst T, Ross BD. Development of the human brain: in vivo quantification of metabolite and water content with proton magnetic resonance spectroscopy. Magn Reson Med 1993;30:424-37

112. Castillo M, Kwock L, Mukherji SK. Clinical applications of proton MR spectroscopy. AJNR Am J Neuroradiol 1996;17:1-15

113. Hurley RA, Ernst T, Khalili K, et al. Identification of HIV-associated progressive multifocal leukoencephalopathy: magnetic resonance imaging and spectroscopy. J Neuropsychiatry Clin Neurosci 2003;15:1-6

114. Brand A, Richter-Landsberg C, Leibfritz D. Multinuclear NMR studies on the energy metabolism of glial and neuronal cells. Dev Neurosci 1993;15:289-98

115. Katz-Brull R, Lenkinski RE, Du Pasquier RA, et al. Elevation of myoinositol is associated with disease containment in progressive multifocal leukoencephalopathy. Neurology 2004;63:897-900

116. Menon DK, Ainsworth JG, Cox IJ, et al. Proton MR spectroscopy of the brain in AIDS dementia complex. J Comput Assist Tomogr 1992;16:538-42

117. Chong WK, Sweeney B, Wilkinson ID, et al. Proton spectroscopy of the brain in HIV infection: correlation with clinical, immunologic, and MR imaging findings. Radiology 1993;188:119-24

118. Tracey I, Carr CA, Guimaraes AR, et al. Brain choline-containing compounds are elevated in HIV-positive patients before the onset of AIDS dementia complex: a proton magnetic resonance spectroscopic study. Neurology 1996; 46:783-88

119. Jarvik JG, Lenkinski RE, Grossman RI, et al. Proton MR spectroscopy of HIVinfected patients: characterization of abnormalities with imaging and clinical correlation. Radiology 1993;186:739-44

120. Chang L, Ernst T, Tornatore C, et al. Metabolite abnormalities in progressive multifocal leukoencephalopathy by proton magnetic resonance spectroscopy. Neurology 1997;48:836-45

121. Nelson PK, Masters LT, Zagzag D, et al. Angiographic abnormalities in progressive multifocal leukoencephalopathy: an explanation based on neuropathologic findings. AJNR Am J Neuroradiol 1999;20:487-94

122. Iranzo A, Martí-Fábregas J, Domingo P, et al. Absence of thallium-201 brain uptake in progressive multifocal leukoencephalopathy in AIDS patients. Acta Neurol Scand 1999;100:102-05

123. Lee VW, Antonacci V, Tilak S, et al. Intracranial mass lesions: sequentia thallium and gallium scintigraphy in patients with AIDS. Radiology 1999; 211:507-12

124. Port JD, Miseljic S, Lee RR, et al. Progressive multifocal leukoencephalopathy demonstrating contrast enhancement on MRI and uptake of thallium-201: a case report. Neuroradiology 1999;41:895-98

125. Koralnik IJ. Progressive multifocal leukoencephalopathy revisited: has the disease outgrown its name? Ann Neurol 2006;60:162-73 